\title{
Omental dirofilariasis caused by Dirofilaria repens; visceralisation in a patient with diabetes mellitus
}

\author{
Weerasekera $C{ }^{1}$, Hapuachchige $C^{2}$, Wijeratne $Y M T Y^{2}$, Goonesinghe $\mathbf{R}^{2}$, Wickremasinghe $\mathrm{DR}^{1}$, \\ Yahathugoda $\mathrm{TC}^{3}$, Ranasinghe $\mathbf{S}^{1}$
}

Journal of the Ceylon College of Physicians, 2021, 52, 105-108

\begin{abstract}
Visceral manifestations due to zoonotic Dirofilaria repens have not been reported in Sri Lanka. A 46-year-old woman with type 2 diabetes mellitus presented with abdominal pain and ankle oedema. There was ultrasonographic evidence of ascites and laparoscopy was performed to exclude malignancy. Cytology of ascitic fluid revealed inflammatory cells, and histology of omental biopsy showed a cross-section of a worm within a granuloma. The presence of cuticular ridges, tall coelomyarian muscles, prominent lateral chords and the presence of developing eggs within a uterine tube was compatible with female Dirofilaria repens. Blood was negative for microfilariae. She was treated with halfdose diethylcarbamazine (DEC) for fourteen days. Ascites persisted, albeit treatment. Therefore, repeat laparoscopy and infracolic omentectomy were performed. Repeat cytology and histology revealed no abnormalities, which was attributed to the complete removal of the worm. Whether immunosuppression with diabetes mellitus led to visceralisation of dirofilariasis is a concern.
\end{abstract}

Key words: dirofilariasis, visceralisation, diabetes mellitus

\section{Introduction}

Dirofilaria immitis and Dirofilaria repens are the commonest Dirofilaria spp affecting humans. The definitive host in these species is the domestic dog, less commonly cats. The larval stage (L3) of Dirofilaria spp., injected into human skin with a bite of an infected mosquito, would usually develop into sexually immature adults and further maturation is arrested. They would either die or remain alive for several months to years within the tissues. ${ }^{1}$ Dirofilaria immitis adult visceralises, preferentially enter the pulmonary circulation, while $D$. repens adults inhabit the subcutaneous tissue both in their definitive hosts and in humans. Dirofilaria repens, therefore commonly gives rise to a subcutaneous lump that may either migrate or remain stationary. A granulomatous mass is typically formed around the live or the dead worm. The patient may present with a lump or nodule with a firm or cystic consistency, and the worm may be visualised with an ultrasound scan. In addition, $D$. repens is known to migrate into several locations in the eye (subconjunctival, subscleral, intravitreal etc.). ${ }^{2}$ Surgical removal of the worm is the treatment of choice.

Infection due to $D$. immitis is more widespread and studied than its counterpart $D$. repens, which is restricted to Europe, Africa and Asia. ${ }^{3}$ Sri Lanka, with its first case reported in 1962, is documented to have the second-highest prevalence of subcutaneous and ocular dirofilariasis cases caused by $D$. repens between 1995-2000. ${ }^{4}$ Several intra-oral cases were reported as well. ${ }^{4}$ Hitherto, visceral manifestations due to Dirofilaria spp. have not been reported from Sri Lanka. Hence, we report a case of omental dirofilariasis due to $D$. repens in a diabetic patient and discuss its possible implications for public health in Sri Lanka.

\footnotetext{
${ }^{1}$ Department of Parasitology, Faculty of Medical Sciences, University of Sri Jayewardenepura, Nugegoda, Sri Lanka , ${ }^{2}$ National Cancer Institute (Apeksha Hospital), Maharagama, Sri Lanka, ${ }^{3}$ Filariasis Research Training and Services Unit, Faculty of Medicine, University of Ruhuna, Galle, Sri Lanka.
}

Correspondence: CJW, e-mail: chamarikajayanetti@sjp.ac.Ik

https://orcid.org/0000-0002-7522-0943

Received 11 August 2021, accepted 20 October 2021

This is an open-access article distributed under the terms of the Creative Commons Attribution License, which permits unrestricted use, distribution, and reproduction in any medium, provided the original author and source are credited. 


\section{Case report}

A 46-year-old woman from Piliyandala, an urban area in the Colombo district, was referred to the Department of Parasitology, Faculty of Medical Sciences, University of Sri Jayewardenepura for further evaluation after a worm was found in a biopsy specimen of the omentum. She was referred from the National Cancer Institute (NCI), Maharagama, where diagnostic laparoscopy was performed to exclude malignancy. Her primary complaints were abdominal pain and bilateral ankle oedema for a one-year duration. Accompanying symptoms included abdominal distension, nausea, loss of appetite and generalised fatigue. She was on treatment for hypertension, hypercholesterolemia and long-standing type 2 diabetes mellitus (DM), which was complicated with nephropathy, neuropathy and retinopathy. She had been repeatedly investigated for bilateral ankle oedema for the past year before being referred to $\mathrm{NCl}$. Since transabdominal ultrasound revealed ascitic fluid in the pouch of Douglas (POD), diagnostic laparoscopy was performed to exclude malignancy. Other than the presence of ascitic fluid in POD, the macroscopy of the abdominal viscera appeared normal. Ascitic fluid and omental biopsy were obtained to exclude primary peritoneal malignancy. Cytology of peritoneal fluid revealed amorphous fluid with scattered reactive mesothelial cells, neutrophils and lymphocytes; malignant cells were not visualised. Histology of omental biopsy showed a cross-section of a worm within a granuloma. The rest of the tissue showed a scattered infiltrate of chronic inflammatory cells with no evidence of malignancy. The worm had cuticular ridges and tall coelomyerian muscles with prominent lateral chords. One of the uterine tubes of the worm contained developing eggs. The morphology was compatible with female $D$. repens (Figure 1).

Thick blood film examination and Knott's concentration, which were carried out on peripheral blood according to standard protocols to exclude probable microfilaraemia, yielded negative results. Blood analysis showed a leucocyte count of $8.8 \times 10^{9}$ and $4.5 \%$ of eosinophils. The patient was treated with half-dose diethylcarbamazine due to nephropathy; $50 \mathrm{mg}$ thrice daily for 14 days to arrest migration and to kill any possible remaining filarial worms. Due to the presence of mesothelial cells in the ascitic fluid, the patient was monitored with a repeat ultrasound scan for improvement/increase in the volume of ascites. Repeat laparoscopy was performed four weeks after completion of treatment to check for any abnormalities in the omentum as ascites persisted. Since no macroscopic abnormalities were detected, infracolic omentectomy was carried out simultaneously (Figure 2). Repeat cytology of the ascitic fluid was normal, and there was no histological evidence of granuloma formation or worms in the removed omental tissue. Since the ascites did not resolve even post-surgery, a renal pathology was suspected, and the patient was referred to a nephrology unit for further management.

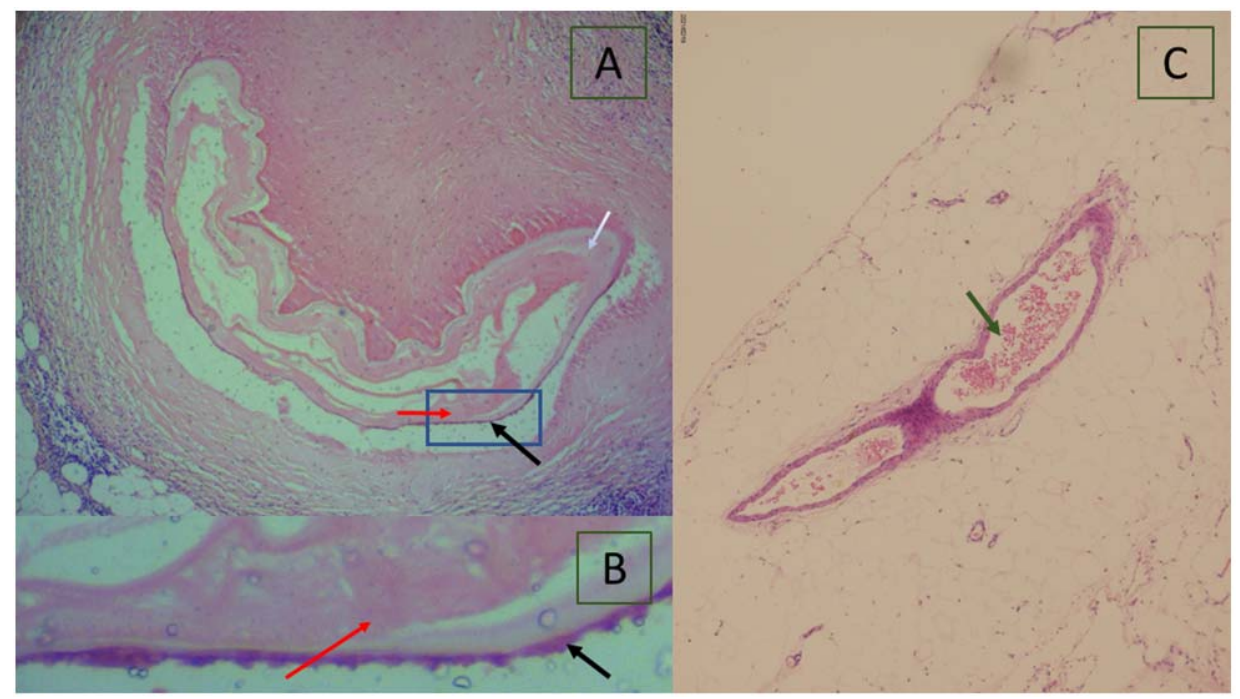

Figure 1. Cross-sectional morphology of the worm identified in the biopsy.

A - The cuticular ridges (black arrow) and the tall coelomyerian muscle cells (red arrow) are seen. The white arrow depicts the lateral chord (10X).

$B$ - The content within the blue box in figure A is enlarged. The cuticular ridges (black arrow) and the tall coelomyerian muscle cells (red arrow) can be seen clearly (40X).

C - Shows uterine tubes with developing eggs (green arrow) (10X). 


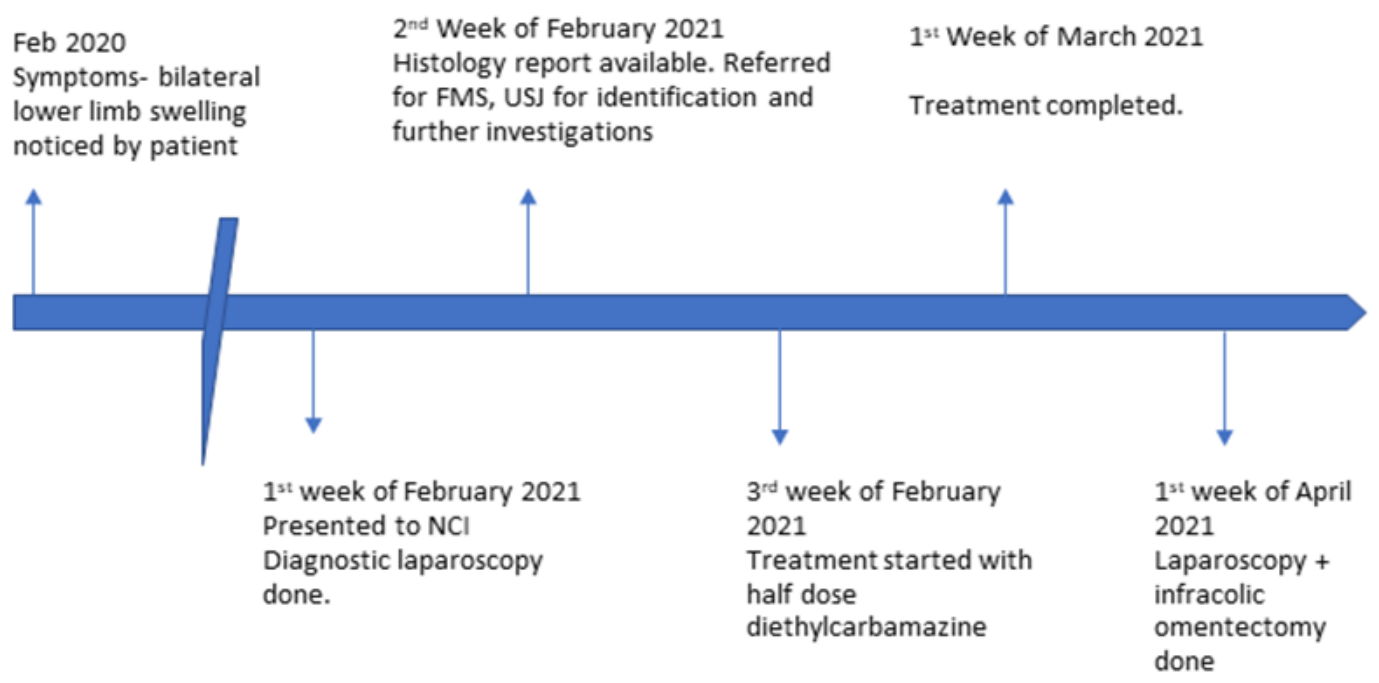

Figure 2. Timeline of important clinical events.

\section{Discussion and conclusion}

Here we report the first endogenous case of omental dirofilariasis, in which very few cases have been reported globally so far; literature reveals only three cases of omental dirofilariasis elsewhere in the world ${ }^{5,6}$. In our patient, detection of the $D$. repens worm in the omentum was an atypical incidental finding, with no macroscopic abnormality detected in the omentum in both laparoscopies. The first biopsy would have partially removed the worm leading to its further disintegration with time, resulting in normal histology in the repeat biopsy. Whether the spread of the worm was through the circulatory system or by direct migration from the subcutaneous tissue, piercing the anterior abdominal wall into the omentum, is unclear. ${ }^{3}$ The absence of microfilaraemia ${ }^{4}$ with an eosinophil count at the upper limit of normal is usually observed in humans dirofilariasis. ${ }^{3}$ However, very rarely, microfilaraemia has been reported in association with subcutaneous lesions. ${ }^{7}$

We used a course of half-dose DEC since there was visceralization to arrest or kill any remaining live worms considering the possible immunosuppressive status of this patient due to DM. Whether DM led to possible visceralization by impairing host immunity needs to be elucidated.

The vectors of dirofilariasis include mosquitoes of the family Culicidae, including Aedes aegypti and Armigeres sulalbatus, frequently found in the urban setting. However, no local studies have incriminated the vector/s of dirofilariasis in Sri Lanka to date. Further, diagnostic facilities are scarce in major hospitals and molecular studies to detect microfilariae in the blood is yet not established in Sri Lanka. However, Departments of Parasitology in all the medical faculties in state universities, as well as the Medical Research Institute, Colombo offer diagnostic assistance. It is recommended that each centre is contacted whenever possible for technological assistance before sending samples.

\section{Conclusions}

Dirofilariasis could be considered as an emerging zoonotic disease in the country and can lead to a challenging public health problem in Sri Lanka in future. Regular screening of dogs and treatment of dogs with ivermectin, vector incrimination and implementing vector control measures, preventing man-vector contact, increasing public and clinician awareness, and expanding diagnostic facilities may be necessary measures needed to be taken to overcome the challenge of spreading this disease.

\section{References}

1. Thomas C. Orihel, Lawrence R. Ash. Parasites in human tissues. Amer Society of Clinical; $1^{\text {st }}$ edition. 1995.

2. Kalogeropoulos CD, Stefaniotou MI, Gorgoli KE, Papadopoulou CV, Pappa CN, Paschidis CA. Ocular dirofilariasis: a case series of 8 patients. Middle East Afr J Ophthalmol. 2014; 21(4): 312-16. doi:10.4103/0974-9233.142267

3. Capelli G, Genchi C, Baneth G, et al . Recent advances on Dirofilaria repens in dogs and humans in Europe. Parasit Vectors. 2018; 11(1): 663. doi: 10.1186/s13071-018-3205-x. PMID: 30567586; PMCID: PMC6299983. 
4. Chandrasena TG AN, Premaratna R, Mallawaarachchi CH, et al. The Diversity of Human Dirofilariasis in Western Sri Lanka, BioMed Research International, 2019, Article ID 9209240, 7 pages.. https://doi.org/10.1155/2019/9209240

5. Pampiglione S, Rivasi F, Angeli G, et al. Dirofilariasis due to Dirofilaria repens in Italy, an emergent zoonosis: report of 60 new cases. Histopathology 2001; 38(4): 344-54. doi: 10.1046/j.1365-2559.2001.01099.x. PMID: 11318900.

6. Fedyanina LV, Maksimova MS. The 15 years' experience of diagnostic of human dirofilariasis. Klin Lab Diagn. 2017;
62(12): 753-7. doi: 10.18821/0869-2084-2017-62-12-753757. PMID: 30856309

7. Raele DAPugliese N, La Bella G, et al. Case Report: Molecular Detection of Dirofilaria repens in an Italian Patient after a Stay in Tanzania. Am. J. Trop. Med. 2021; 104(6): 2042-5.

8. Dissanaike S, Abeyewickreme W, Wijesundera MD, Weerasooriya MV, Ismail MM. Human dirofilariasis caused by Dirofilaria (Nochtiella) repens in Sri Lanka. Parassitologia 1997; 39(4): 375-82. 